\section{Tracheo-bronchial involvement in Sweet syndrome}

A 70-year-old man with myelofibrosis and Sweet syndrome (acute febrile neutrophilic dermatosis) presented with a 2 month history of cough with bloody sputum (figure 1). No infiltration was visible on a chest radiograph.

On bronchoscopic examination, a centrally depressed macular lesion with an eroded surface was revealed in the anterior tracheal wall, as well as several scattered erosions in the trachea and bronchi (figure 2A). A biopsy specimen of the tracheal lesion showed dense inflammatory infiltrates with intercellular oedema and some leucocytoclasis. Despite dense inflammatory infiltrates mainly consisting of neutrophils, there was no evidence of vasculitic changes (figure 3A). These histological characteristics of the tracheal lesion were similar to those of skin lesions in Sweet syndrome (figure $3 \mathrm{~B}$ ). Aetiological investigations yielded negative results, but the anti-Chlamydophila pneumoniae immunoglobulin (IgM) titre was elevated. Symptoms remained aggravated despite azythromycin treatment. Oral prednisolone at $30 \mathrm{mg}$ daily was started and then tapered. The patient's symptoms decreased and the lesions showed scarring on bronchoscopic examination following this treatment (figure $2 \mathrm{~B}$ ).

Sweet syndrome is often associated with haematopoietic malignancy and myeloproliferative disorders such as myelofibrosis. ${ }^{1}$

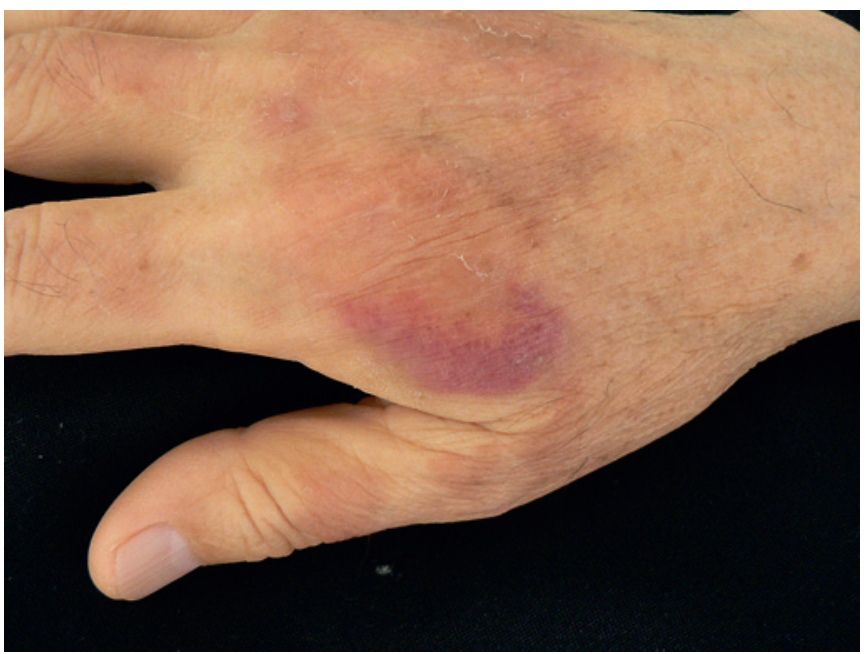

Figure 1 A well-defined erythematous plaque on the dorsal surface of the hand.
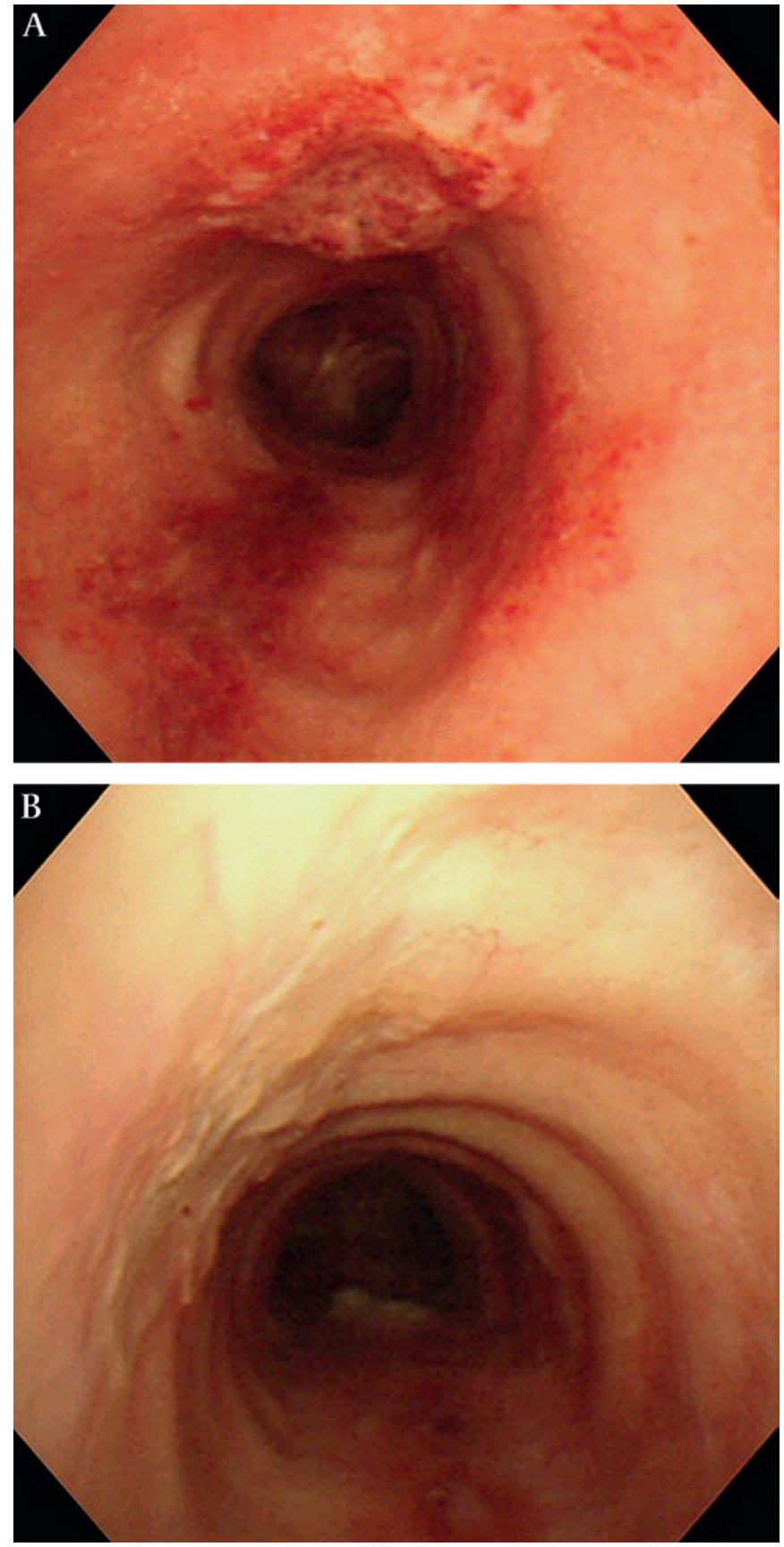

Figure 2 Images from bronchoscopic examination before $(A)$ and after (B) corticosteroid treatment.

Figure 3 (A) A bronchoscopic biopsy specimen of the tracheal lesion showing dense inflammatory infiltrates without vasculitic changes. (B) A biopsy specimen of the skin lesion showing the same characteristics. 
Its pathogenesis is not definitively determined but it is postulated to be a multifactorial process involving a hypersensitivity reaction and cytokine dysregulation. Sweet syndrome can include internal organ involvement. In the literature, there is only one report of bronchial involvement, but that was associated with pulmonary infiltration. ${ }^{2}$ In the present case, tracheo-bronchial involvement without pulmonary infiltration may have been induced locally by chlamydophilal tracheobronchitis.

\section{Kazuya Tanimura, Hideo Kita, Yoshihiro Kanemitsu,} Yoshinori Fuseya, Yuko Katayama

Department of Respiratory Medicine, Takatsuki Red Cross Hospital, Takatsuki city, Osaka, Japan
Correspondence to Dr Kazuya Tanimura, Department of Respiratory Medicine, Takatsuki Red Cross Hospital, Abuno 1-1-1, Takatsuki city, Osaka, 569-1096, Japan; tanigue1981@yahoo.co.jp

Competing interests None.

Patient consent Obtained.

Provenance and peer review Not commissioned; externally peer reviewed.

Accepted 25 May 2010

Published Online First 6 September 2010

Thorax 2010;65:1119-1120. doi:10.1136/thx.2009.133256

\section{REFERENCES}

1. Cohen PR, Talpaz M, Kurzrock R. Malignancy-associated Sweet's syndrome: review of the world literature. J Clin Oncol 1988;6:1887-97.

2. Thurnheer $\mathbf{R}$, Stammberger U, Hailemariam S, et al. Bronchial manifestation of acute febrile neutrophilic dermatosis (Sweet's syndrome). Eur Respir J 1998;11:978-90. 